\title{
El bufeo colorado en dos novelas amazónicas peruanas
}

\section{The bufeo colorado in some Peruvian Amazon novels}

\section{Stefano Pau}

Università degli Studi di Napoli Federico II, Nápoles, Italia

Contacto: stefano.pau@unina.it

https://orcid.org/0000-0002-6485-6567

\section{RESUMEN}

El bufeo colorado (Inia geoffrensis) es el delfín rosado que vive en los ríos de la cuenca amazónica y es el protagonista de una de las más difundidas narraciones de la tradición oral de las poblaciones indígenas y ribereñas de la zona, para las que posee facultades metamórficas. El bufeo, de hecho, puede transformarse en un hombre de rasgos occidentales, un "gringo" alto, muchas veces rubio y con los ojos claros y, frecuentemente, se indica como el padre de los niños de los que se ignora la paternidad. En este trabajo se traza una panorámica de su presencia en algunas novelas ambientadas en la selva, para demostrar cómo los autores -en la mayoría de los casos- aprovechan este relato exclusivamente para perpetuar estereotipos sobre la selva vista como "infierno verde" y sobre la sexualidad de sus habitantes. En contraste, se enseñarán dos casos, los de las novelas Paiche de César Calvo de Araújo y La virgen del Samiria de Róger Rumrrill, en los que se deconstruye el mito y se apunta a una descripción más objetiva de la selva. En estas dos obras, en efecto, los autores explican de manera explícita la carga metafórica del relato, desvelan la violencia que se halla detrás de su creación, lo contextualizan y explican sus funciones en el ámbito social, contribuyendo de esta manera a un acercamiento más equilibrado al mundo amazónico.

Palabras clave: Bufeo colorado; Violencia; Paiche; La Virgen del Samiria; Amazonía peruana

\section{ABSTRACT}

The bufeo colorado (Inia geoffrensis) is the pink dolphin that lives in the rivers of the Amazon ba$\sin$. It is the protagonist of one of the most widespread tales in the oral tradition of the indigenous and riverine populations of the area, for whom it possesses metamorphic powers. The bufeo, in fact, can turn into a man with western features, a tall "gringo", often with blond hair and light-coloured eyes, and is often indicated as the father of children whose paternity is unknown. This paper will outline its presence in some novels set in the jungle, in order to show how the authors -in most cases - use this story exclusively to perpetuate stereotypes about the jungle as a "green hell" and about the sexuality of its inhabitants. In contrast, two cases will be shown, those of the novels Paiche by César Calvo de Araújo and La virgen del Samiria by Róger Rumrrill, which deconstruct the myth and aim for a more objective description of the jungle. In these two works, in fact, the authors explicitly explain the metaphorical content of the story, unveil the violence behind its creation, contextualise it and explain its social functions, thus contributing to a more balanced approach to the Amazonian world.

Keywords: Bufeo colorado; Violence; Paiche; La Virgen del Samiria; Peruvian Amazon 


\section{Introducción}

El bufeo colorado (Inia geoffrensis) es el delfín rosado que vive en las aguas de los ríos de la cuenca amazónica y es el protagonista de una de las más conocidas narraciones de la tradición oral de las poblaciones autóctonas y ribereñas de la selva ${ }^{1}$.

A diferencia del bufeo gris, normalmente amigo y colaborador de los seres humanos, el bufeo rosado es un ser engañador y generalmente negativo. Como señala Jaime Regan:

Los colorados son malos y se convierten en gente que engaña a los humanos. Los machos buscan a las mujeres y las hembras buscan a los hombres. Salen a la ciudad, a las chacras y persiguen a las mujeres que viajan en canoa. (1983, p. 177)

Las versiones del relato son muchas y su difusión traspasa las fronteras de los países amazónicos, encontrándose ejemplos no solo en Perú (Belaunde, 2005, Belaunde, 2018; Regan, 1983; Valenzuela \& Valera, 2005, pp. 321-326), sino también en Brasil (Câmara Cascudo, 1999, pp. 181-185; Slater, 1994), Colombia (Cure Valdivieso, 2005; Omacha, 2004) o Ecuador (Galli, 2012), especialmente "a lo largo de los grandes ríos con intenso comercio fluvial proveniente de los centros urbanos" (Belaunde, 2005, p. 252).

En la versión más difundida del relato, el bufeo tiene la capacidad de transformarse en un hombre de rasgos occidentales, un "gringo" alto, muchas veces rubio y con los ojos claros, elegante y fascinante, experto bailarín que, especialmente durante las fiestas en las comunidades, sale del río con el objetivo de seducir a las chicas. La chica elegida no puede oponerse a sus encantamientos, y le sigue hacia su ciudad bajo el agua. Esta ciudad se suele describir como una ciudad real, con calles, edificios, alumbrado eléctrico, hospitales, infraestructuras modernas (Belaunde, 2005, p. 252; Cure Valdivieso, 2005, p. 62).

Luisa Elvira Belaunde y Regan indican, además, que en los testimonios recogidos en las comunidades indígenas, de manera diferente a las recopiladas entre la población ribereña, "el factor principal que desencadena la aparición del bufeo bajo forma humana es el olor de la sangre menstrual" (Belaunde, 2018, pp. 110-111), por eso "muchas mujeres evitan ir a lavarse y a lavar la ropa al río cuando están con la menstruación porque el bufeo percibe el olor de muy lejos" (Regan, 1983, p. 177).

De las ciudades bajo el agua a las que son llevadas por el bufeo, en muchos casos, las muchachas vuelven embarazadas. De esta manera, "los niños de piel, cabello y ojos claros son comúnmente llamados "hijos del bufeo"' (Belaunde, 2005, p. 49; 2018, p. 114).

Los relatos sobre el bufeo colorado son realmente muy difundidos y, como para muchos relatos de la tradición oral amazónica, aparecen también al interior de obras de literatura escrita. En algunos casos se configuran como temas de narraciones que reinterpretan la historia popular; pero, en muchas otras ocasiones, aparecen tan solo como referencias exotizantes que raramente afectan la diégesis y el desarrollo de la historia.

En estos últimos casos el aprovechamiento de este recurso literario comporta la perpetuación de algunos de los estereotipos más arraigados sobre Amazonía y sus moradores, como por ejemplo, el del "infierno verde" ${ }^{\prime}$, en segundo lugar, y conectado con lo antecedente, "la representación hipersexualizada de la región amazónica y sus mujeres" (Motta, 2011, p. 32; cfr. también Barletti, 2004; Chirif, 2004; Varela, 2004); es decir, la representación de un espacio en el que las pasiones desenfrenadas delatan el supuesto salvajismo de los moradores y las moradoras, a quienes hay que civilizar y domesticar.

Sin embargo, a lo largo de este trabajo se enseñarán algunos casos procedentes de dos novelas - Paiche de César Calvo de Araújo y La virgen del Samiria de Róger Rumrrill- en las que la carga metafórica del relato del bufeo colorado es revelada; es decir, que se explican de manera explícita las posibles razones por las que este relato surgió y se evidencia la violencia que subyace a su difusión. Planteamos, entonces, que tal "desmetaforización" y "desmitificación" puede proporcionar una representación más objetiva de la selva y de las maneras de interpretar el mundo de sus habitantes, alejándose de esta manera de las imágenes estereotipadas y de las descripciones polarizadas y connotadas negativamente.

\section{Relaciones interespecíficas ${ }^{3}$}

El relato "mítico" sobre el bufeo colorado, a la par 
de muchos otros elementos que forman parte de las cosmovisiones indígenas amazónicas, no es percibido tan solo como un simple cuento (Magalhães Lima, 2014). La recepción y percepción de los que han sido clasificados según esquemas occidentales como "mitos" va mucho más allá de la literariedad, rompe la barrera que los separa de la historicidad y los conforma como componentes de la realidad. Una distinción entre mitos y realidad histórica, de hecho, tiene poco sentido, puesto que - en muchos casosfragmentos de mito forman parte de narraciones que percibimos como historia (Reeve, 1988, p. 21) y amplían sus niveles de significado y su relativa comprensión, y lo que habitualmente se define como historia está intercalada por un gran número de actividades sociales; como señala Manuela Casu (2015, pp. 72-73) el mito es una experiencia y el relato - oral u escrito - es justamente eso: un relato con contenido mítico.

En las sociedades amazónicas, al fundir las dos vertientes, se superaría la dicotomía establecida por los antropólogos estructuralistas que definían la historia como una serie cronológica de acontecimientos y el mito como un orden atemporal e irracional, representación de sociedades inmóviles y "congeladas" en el tiempo (Lévi-Strauss, LéviStrauss, 1955; Lévi-Strauss, 1962; Lévi-Strauss, 1964; Lévi-Strauss, 1966; Lévi-Strauss, 1968; LéviStrauss, 1971; Pineda Camacho, 2010, p. 98). Esta concepción fue criticada duramente en los años ochenta por algunos antropólogos estadounidenses (Hill, 1988), quienes sugerían que mito e historia no son formas de conocimiento incompatibles o situadas en dos supuestos niveles evolutivos consecutivos, sino elementos complementarios y paralelos (Turner, 1988, p. 237). De forma parecida lo explica Rama (2008):

El pensamiento mítico no es una peculiaridad exclusiva de las sociedades arcaicas o primitivas o de culturas no occidentales, pudiéndose reconocerlo aun en las sociedades más avanzadas, separado o confundido con formas del pensamiento que llamamos científico, del cual se distingue, no por sus mecanismos o formas abstractas, que son los mismos, sino por los distintos campos y materiales con que se trabaja. (pp. 328-329)
Por todas estas razones, parece útil abandonar definiciones que no describen satisfactoriamente estas creaciones. De hecho, tanto "mito", como "relato mítico" o "relato de la tradición oral" parecen ser no totalmente pertinentes para su definición, porque "el mito es la organización de los elementos del universo mediante la palabra" (Urteaga Cabrera, 1995, p. 12). Por lo tanto, en espera de definiciones más oportunas y apropiadas, de una "descolonización [...] de la lengua con la que nombramos al mundo" (Rivera Cusicanqui, 2010, p. 71), proponemos definir estas componentes creativas indígenas como "realidades simbólicas alternativas" (Pau, 2019a, p. 94), subrayando de esta manera el elemento simbólico y metafórico que constituye la esencia primaria de este tipo de creaciones, asimilables a unos relatos, pero que transcienden la mera literariedad ocupando un espacio intermedio entre ella y la realidad factual.

En el caso del bufeo colorado la conexión con la vida real tiene que ver principalmente con casos de relaciones coercitivas y violaciones, y la consecuente existencia de numerosos casos de madres-solteras. Tales problemáticas ligadas a la reproducción se han intensificado principalmente a partir de la invasión occidental de la selva empezada a raíz del boom del caucho y que ha continuado, con diferente intensidad, hasta el día de hoy. Como señala Belaunde (2018):

[...] la mayoría de las ciudades amazónicas que surgieron durante o después del auge cauchero de los siglos XIX y XX, se caracterizan por tener un comercio sexual pujante para satisfacer la demanda de la población migrante proveniente de otros lugares del país o del extranjero y, en gran parte, masculina, que llega a la selva en busca de nuevos recursos económicos y de nuevos placeres. (p. 92)

La estrategia llevada a cabo al interior de las sociedades indígenas amazónicas para hacer frente a los traumas procedentes de estas situaciones se inserta en una categoría de narraciones en la que las mujeres mantienen relaciones sexuales y son embarazadas por unos animales que se presentan a ellas con el aspecto de seres humanos (Galli, 2012, p. 423; Magalhães Lima, 2014; Slater, 1994).

Para muchas de las sociedades originarias amazónicas, en efecto, la frontera ontológica entre los 
varios seres que habitan el cosmos se puede franquear frecuentemente, ya que todos los seres compartirían principios y características comunes y parecen estar diferenciados solamente por su aspecto exterior; es decir, lo que el antropólogo Eduardo Viveiros de Castro llama "ropa" (2004, p. 39). Así, a muchos seres se les reconocen comúnmente capacidades metamórficas:

[...] los humanos pueden convertirse en animales, los animales en humanos, y el animal de una especie transformarse en animal de otra especie. Por tanto, la influencia taxonómica sobre lo real es siempre relativa y contextual, y el trueque permanente de las apariencias no permite atribuir identidades estables a los componentes vivos del entorno. (Descola, 2004, p. 28)

Cambiar de aspecto exterior no conlleva, sin embargo, un cambio en esa condición originaria interior común, esa "humanidad" que caracteriza a todos (o casi todos) los seres del cosmos (Descola, 2002; 2004; 2012): "habiendo sido en otro tiempo humanos, los animales y otros seres del cosmos continúan siendo humanos, aunque de modo no evidente" (Viveiros de Castro, 2004, p. 42). Así, Viveiros de Castro anota que algunos animales, los espíritus y todos los agentes que habitan el cosmos se perciben a sí mismos como humanos, porque son esencialmente humanos: "son gente" (Viveiros de Castro, 2004, p. 49), "son personas" (Viveiros de Castro,2010, p. 35).

El mismo concepto lo expone el maestro y periodista de origen kukama y achuar Leonardo Tello, quien subraya también cómo se puede cruzar la sutil línea que separa una especie de otra:

[...] un chamán se puede convertir en espíritu o animal; una persona se puede convertir en animal: la cutipa. [...] Un espíritu se puede presentar como persona: karwara (gente del agua) se presenta como si fuera un familiar o amigo del pescador-recolector para que le acompañe y se quede a vivir en el agua; de igual manera los bufeos que se convierten en "gringos" en las noches y acuden a las fiestas para enamorar jovencitas. (Tello, 2014, pp. 40-41)

Como indica Belaunde, "cuando una mujer se enamora de un bufeo, deja a los suyos para seguirlo, para después regresar desilusionada con un niño mestizo en brazos" (2005, p. 310). El fruto de la relación entre una mujer y un delfín es en muchos casos una criatura que está a mitad entre el mundo animal y el humano y que, por ende, no tiene la capacidad para sobrevivir en el mundo sensible. Elisa Galli, por su parte, presenta algunos casos de mujeres quichua que, después de haber soñado repetidamente con tener relaciones sexuales con un "gringo", se quedaron embarazadas y dieron a luz hijos especiales, por ejemplo con los ojos transparentes o, en los casos más extremos, con características físicas típicas de los delfines (2012, p. 425). Según Galli (2012), los hijos nacidos de la unión de una mujer con un bufeo, por el hecho de no pertenecer ni a una especie ni a la otra, raramente sobreviven y, a menudo, abandonan su familia para volver a su mundo (p. 426).

Ya en los años ochenta, Regan (1983) transcribió varios testimonios acerca del bufeo colorado y, entre ellos, dos llaman particularmente la atención (pp. 176-185). El primero relata la unión de una mujer con este animal durante la ausencia del marido, ocupado en el trabajo de extracción del caucho, mientras que el segundo acontece de manera similar en una zona petrolera a orillas del río Tigre.

En efecto, la llegada a la selva de los trabajadores caucheros de origen europeo y criollo llevó, entre las varias formas de violencia ejercidas en contra de los pueblos autóctonos, también a una profunda alteración de las relaciones sociales entre hombres y mujeres, en particular con la difusión de prácticas sexuales coercitivas o mercenarias que, con algunas diferencias, se han extendido hasta el día de hoy. La presencia cada día más constante de forasteros en los territorios de la floresta se ha vuelto - en ocasiones - un peligro para las mujeres amazónicas, frecuentemente víctimas de extranjeros-bufeos. Para defenderse de las consecuencias de estas relaciones de poder desproporcionadas ha surgido una realidad simbólica alternativa en la que un animal - el delfín en este caso - es el responsable de la seducción.

Estos relatos sirven, justamente, para dar sentido a los acontecimientos que trastornan la vida en la región amazónica. Como señala Candace Slater (1994), se trata de una reacción (no siempre consciente, aunque no por ello menos fuerte) al orden económico capitalista que hace cada vez más insostenible la vida en el campo y a la visión racionalista del mundo que la 
acompaña (p. 2). Los relatos tienen como finalidad la de aliviar una realidad terrible, de moderar y mitigar tensiones; hacen que se pueda aceptar con menor dificultad las violaciones y - frecuentementecontribuyen a interrumpir una cadena de actos violentos que, de otra forma, podrían convertirse en un círculo vicioso interminable .

Quedar embarazada por parte de un animal no tiene la misma carga negativa que estarlo a causa de un estupro perpetrado por un extranjero (y en este sentido no importa que se trate de un cauchero de comienzos del siglo XX o de un turista en la actualidad). De la misma manera, interrumpir la gestación no deseada conlleva menos sentido de culpabilidad, si el ser que se decide abortar no es humano, sino un híbrido que no tendría posibilidades de vivir una vida normal. A la vez, Belaunde (2018) indica, además, una correlación entre la figura del bufeo y el abandono de las prácticas de restricciones sexuales rituales de las mujeres indígenas. Esta quiebra "vulnerabiliza a las personas indígenas, y las coloca en la posición de presa del colonizador" (pp. 114-115).

\section{El bufeo colorado en la literatura escrita}

La difusión de esta realidad simbólica alternativa es tan grande que en muchas obras narrativas ambientadas en la Amazonía se encuentran frecuentemente referencias y alusiones. Sin embargo, en la mayoría de los casos, el relato de la tradición oral no tiene ningún efecto sobre la economía diegética de las novelas y los cuentos, y es usado exclusivamente como un recurso exótico que contribuye a la creación de un imaginario distorsionado del espacio amazónico. Se percibe, así, falta de sensibilidad y de interés por parte de los autores para adentrarse a fondo en la cuestión y entender su alcance en los ámbitos personal y social.

Una muestra de esta postura se encuentra, por ejemplo, en El bosque que llora de Vicky Baum (1961, p. 106), una de las más conocidas novelas sobre la época del caucho. La alusión al bufeo colorado se presenta tan solo como un guiño para el lector occidental, que disfruta del imaginario misterioso de lo que podría percibirse como mera superstición, sin poder acceder a ninguna información que le ayude a comprender el contexto en el que surge. Encontramos así un breve diálogo entre un joven brasileño que está a punto de empezar a trabajar como peón cauchero y que intenta seducir a una mujer por las calles de Belem do Pará:

$$
\begin{aligned}
& -¿ \text { ¿Es usted forastero? ¿Quizás un boto? } \\
& \text { - ¿Por qué un boto, señorita? }
\end{aligned}
$$

- ¿No sabe lo que dicen de los botos en todo el Amazonas? Durante el día, son delfines y juegan en los ríos. Pero de noche se transforman en forasteros robustos y bien parecidos que visitan las aldeas, seducen a las muchachas, se van por la mañana y nunca vuelven. Muchísimas muchachas se han quedado con hijos de semejantes botos... o, al menos, así lo dicen ellas. (Baum, 1961, p. 106)

La popular escritora austriaca presenta en pocas líneas una síntesis completa del relato, mencionando también los embarazos consecuentes a las "seducciones". Lo que más llama la atención, no obstante, es la alusión a la mentira: "así lo dicen ellas". La frase, más que indicar la posibilidad de que la historia sirva para difuminar la violencia, aparece como un acto de acusación hacia el supuesto libertinaje de las mujeres amazónicas.

El segundo ejemplo, que no se escapa de la tentación de mencionar el rico imaginario sobre el cetáceo amazónico, lo proporciona Mario Vargas Llosa en Pantaleón y las visitadoras (1981 [1973]). En este caso, el protagonista de la novela envía un informe a sus superiores para informarles que:

En toda la Amazonía existe la creencia de que la variedad colorada del bufeo (pez-delfín de los ríos amazónicos) es un animal de una considerable potencia sexual, la misma que lo induce, con ayuda del demonio o espíritus malignos, a raptar cuanta mujer pueda a fin de satisfacer sus instintos, adoptando para ello una forma humana tan varonil y apuesta que ningún ente femenino se le resiste. Que debido a dicha creencia se ha generalizado esta otra: que la manteca del bufeo incremente el ímpetu viril y hace al varón irresistible a la hembra, siendo por eso un producto de enorme demanda en tiendas y mercados. (p. 88)

Según la visión del militar Pantaleón Pantoja, las seducciones obradas por el bufeo son 
creencias, supersticiones que - una vez mássirven para confirmar la desenfrenada pasión de los amazónicos y las amazónicas. Aun reconociendo un intento crítico y burlesco en la novela de Vargas Llosa, la misma obra contribuye a la difusión y perpetuación de los estereotipos de argumento sexual en la Amazonía: la supuesta sexualidad desordenada y excesiva de los pobladores selváticos estaría así estrechamente conectada al imaginario de primitivos y salvajes con el que han sido asociados desde los primeros contactos con los occidentales (Belaunde, 2018, p. 92; cfr. también Barletti, 2004; Chirif, 2004).

Así, la selva misma resulta ser el espacio en el que las pasiones se despiertan (Pratt, 2010, p. 230) y son llevadas a extremos incontrolables, el elemento activo que tiene un influjo pernicioso sobre la conducta de los seres humanos ${ }^{5}$, proponiendo la enésima versión del dualismo civilización/barbarie. El dossier del protagonista vargasllosiano termina aconsejando la prohibición de la manteca de bufeo para la preparación de los alimentos de los soldados que obran en los cuarteles amazónicos, para evitar que su apetito sexual se desmesure y sea necesario contratar a más visitadoras (Vargas Llosa, 1981 [1973], p. 89).

El tema de los efectos y de los poderes de algunas partes del cuerpo del bufeo (en particular de los especímenes hembras) es retomado también por el poeta César Calvo Soriano en su novela Las tres mitades de Ino Moxo y otros brujos de la Amazonía. La primera referencia se encuentra al comienzo de la obra, cuando el autor enumera la rica fauna amazónica y, al hablar del bufeo, describe la pusang $a^{6}$, un poderoso amuleto utilizado para atraer al sexo opuesto, creado con la vagina del bufeo hembra:

[...] el bujéo, también nombrado delfín de los ríos, el bujéo cuya hembra es más deliciosa en amor que las mujeres, más rica, así dicen los pescadores que han probado, y tiene igual vagina y pechos duros y pare a sus hijitos como humana. Cortándole a una bujéa los labios de su abajo, de su sexo, y curándolos algunos shirimpiáre fabrican pulseras infalibles en asuntos de amantes desdeñados, eso es sabido. (Calvo Soriano, 1981, p. 25)
Sin embargo, al referir el relato sobre el transformismo del bufeo en el glosario situado al final de la obra, Calvo Soriano delata una diferencia de postura con respecto a los ejemplos anteriores: no lo presenta como algo que se dice o se cuenta, como una creencia, sino como algo certero, como la realidad que todo el mundo conoce:

Es cosa resabida que los bufeos machos pueden, si así lo quieren, convertirse en personas: disfrazados de gente salen de los ríos, especialmente en época de fiestas, y protegidos por la algarabía, la confusión, los bailes, galantean muchachas y al final se las roban. Los bufeos, mejor que los humanos preparados, ocupan sin esfuerzo cualesquier apariencia. Pero [...] hagan lo que hagan, sean quienes sean, los bufeos están condenados a llevar sombrero siempre. Así como el chullachaki de humano es delatado por la huella de tigre o de venado que no puede esconder de su pie derecho, el chullachaki de bufeo se ve forzado a respirar por ese inocultable orificio que tiene en la cabeza. Para reconocerlos y espantarlos basta pues con quitarles el sombrero. (Calvo Soriano, 1981, pp. 328-329)

Las palabras del autor y de sus personajes, así, no marcan ninguna distancia con las concepciones y las interpretaciones de la realidad de los moradores de la selva. Esto contribuye a que la obra de Calvo Soriano constituya uno de los ejemplos de mayor éxito en la representación literaria del espacio amazónico. Las tres mitades tiene el mérito de describir la selva sin caer en lo exótico y en el folclor, a pesar de tener como eje fundamental algo tan peculiar como la medicina tradicional, las plantas sagradas y las percepciones ultrasensoriales.

\section{Deconstruyendo el mito}

Abandonar las descripciones estereotipadas sobre la selva y en particular rescatar su potencial positivo, opuesto a la imagen infernal, caótica, que caracterizaba obras tan famosas como La Vorágine del colombiano José Eustasio Rivera, la recopilación de cuentos titulada Toá o incluso Sangama de Arturo Hernández, es el propósito declarado de dos novelas ligadas por un hilo común: Paiche (2012 [1963]) de César Calvo de Araújo y La Virgen del Samiria (2012) de Róger Rumrrill García? 
Las dos novelas, a pesar de haber sido escritas y publicadas a distancia de muchas décadas, comparten algunas inquietudes y un mismo afán por valorizar y reconocer el ambiente amazónico y sus habitantes. En ambas obras los autores se preocupan y denuncian la desequilibrada distribución del trabajo y de los recursos, la explotación, el racismo y las discriminaciones, el extractivismo que descuida el medio ambiente y la contaminación que perjudica las condiciones de vida de los habitantes de la selva.

Paiche es una novela realista escrita en 1942 y que, según las palabras del mismo autor, no iba a ser publicada. En efecto, salió solamente en 1963, cuando Calvo de Araújo se vio "obligado" a publicarla "a fin de que la verdad de la Selva Peruana no siga sufriendo alteraciones dañinas" (Calvo de Araújo, 2012 [1963], p. 254). En la obra, el autor describe la cotidiana lucha por la supervivencia de un grupo de personas que intentan escaparse de la llegada del capitalismo a la selva dando vida a una comunidad socialista que llamarán, justamente, Paiche $^{8}$ (Pau, 2017; 2019b; 2020). Se presenta en ella lo que Jorge Marcone (1998) ha definido como un "retorno a lo natural", es decir, esa actitud de condena de las industrias extractivas que caracterizaba algunas "novelas de la selva" publicadas en esos mismos años; sin embargo, la propuesta de Calvo de Araújo parece novedosa justamente por el hecho de indicar un modelo nuevo y un acercamiento que, en la mayoría de los casos, intenta presentar de manera más completa la visión del mundo propia de la población amazónica.

La Virgen del Samiria fue publicada en 2012 y constituiría, según las intenciones iniciales de su autor, el primer tomo de una trilogía. Es una obra que se basa en el principio de la circularidad del tiempo y que, por eso, se desarrolla en un doble plano temporal, en dos épocas caracterizadas por el aprovechamiento de los recursos naturales y humanos de la selva: el boom del caucho de comienzos del siglo XX y el boom del petróleo de los años sesenta y setenta. Rumrrill introduce en la novela numerosos factores que apuntan a una descripción total de la vida y de la cultura amazónica, tal y como elementos de la cosmovisión indígena (en particular del pueblo Kukama), acontecimientos históricos fundamentales, descripciones de la inmensa riqueza natural de la selva y de las costumbres de sus moradores, desde los hábitos alimentarios hasta la importancia de las prácticas chamánicas.

La novela sigue una tesis fundamental: los ciclos económicos basados en el saqueo de los recursos provocan consecuencias negativas decididamente mayores respecto a los posibles beneficios, causando la destrucción de la naturaleza y la desestructuración de la sociedad. Tal desestructuración es debida principalmente a relaciones desequilibradas de poder, de las que las violaciones y las relaciones coercitivas y mercenarias entre hombres y mujeres representan posiblemente uno de los grados más altos. Esas mismas relaciones que han sido reelaboradas metafóricamente con la creación de la realidad simbólica alternativa del bufeo colorado.

En la novela de Calvo de Araújo se aborda el tema según la perspectiva émica, que permite un acercamiento desde la misma filosofía y cosmovisión amazónica. Uno de los personajes va contando la presencia de los bufeos a Sojo Arimuya, el protagonista:

- Para ellos no es nada el agua: hasta sus candela arde ahí adentro del río y... cuando queren mufer, salen al canto los condenados y agarran cualquier mufer o muchacha questá labando sus ropa o cuando sestán bañáaandooose las pobre. Les jualan de sus brazo y quedan para ellos. Ahí mismito que se cayen en el río, ellas tamién ya saben bibir en el agua y se quedan de mufer de ellos. [...]

- ¡Vaya, vaya! Eso que me cuentas no lo había oído nunca. Yo he viajado por jtantos ríos y nadie, pero nadie, me había contado algo así tan curioso, tan fantástico! ¡Caramba! Cuántas cosas habrá, cuantas cosas que no sabemos que existen! (2012 [1963], p. 78)

En este caso, como en el ejemplo sacado de la novela de su hijo, Calvo de Araújo subraya la existencia, la percepción real de las seducciones del bufeo, a pesar de no mencionar las transformaciones del cetáceo en un hombre blanco. A través de las palabras del protagonista, en efecto, el autor no solo expresa el punto de vista común en el ambiente amazónico, sino que indica además cómo las personas que desconocen la vida en la Amazonía desconocen también la realidad simbólica alternativa. Incluso el empleo del adjetivo "fantástico", en este 
caso, no conlleva ningún matiz despectivo ligado a la imposibilidad o al absurdo, sino que apunta a subrayar lo sorprendente de algo que, sin embargo, acontece.

La perspectiva externa al mundo amazónico aparece, al contrario, en la primera referencia al bufeo colorado presente en la novela de Rumrrill, en un diálogo entre la protagonista de la novela, María Reátegui Torres (una joven que ha llegado a ser, en contra de su voluntad, una visitadora en los campamentos petroleros) y un ingeniero, quien relata a la chica su versión de la realidad simbólica alternativa:

[Él] me contó que al inicio del ciclo petrolero muchos niños rubios, pacuchos y mutishcos nacieron en los pueblos cercanos a los campamentos petroleros.

- ¿Por qué tu hijo ha salido pucacho, rubio y mutishco si su padre es pispachito? - les preguntaban a las madres, muchachas jóvenes y guapas.

- Me ha cutipado el bufeo colorado - contestaban ruborizadas las mujeres, culpando a los delfines rojos del color rubicundo de sus hijos, porque éstos transmiten sus características cuando las mujeres en estado de embarazo los ven en el río, según las creencias mágico-míticas de la cosmovisión amazónica.

- La verdad es que las muchachas sacaban la vuelta a sus maridos que estaban de trocheros en las líneas, con los gerentes y técnicos gringos de las compañías. El puca bufeo o delfín colorado pagaba los platos rotos de los 'cuernos' - concluía el ingeniero Barcia, riéndose a carcajadas. (Rumrrill, 2012, p. 98)

Las palabras del ingeniero dan un vuelco a las relaciones violentas y las describen como episodios de traición por parte de las mujeres. De manera implícita, el personaje subraya y reafirma así el estereotipo de la "charapa ardiente" (Chirif, 2004; Motta, 2011): la culpa del nacimiento de hijos procedentes de relaciones con extranjeros sería entonces exclusivamente de las mujeres y de su supuesta actitud disoluta. En contra de esta visión, algunas páginas después, Rumrrill presenta un caso diametralmente opuesto, acaecido en el otro plano temporal, el de la época del caucho, y que tiene como protagonista al abuelo de María, el capataz Alejandro Reátegui Reátegui.

Este llega moribundo a causa de la mordedura de una serpiente shushupe (Lachesis Muta) a Achual Tipishca, el poblado más importante del pueblo Kukama. Los moradores de la comunidad no tardan en reconocer al cruel capataz que obligaba a muchos kukama al trabajo forzoso en las estradas de propiedad del alemán Hans Heinz, del que era fiel servidor y ejecutor. Un hombre toma entonces la palabra y relata cuál era la tarea principal de Reátegui: capturar a jóvenes muchachas para satisfacer los apetitos sexuales de su jefe. Sucesivamente, el hombre cuenta uno de los muchos episodios de abusos cometidos en contra de jovencitas indígenas y, de entre la gente que está escuchando, sale entonces una joven muchacha, que relata su propia historia: es una de las muchas víctimas de Heinz. Una noche, después de haber sido violada por enésima vez, aprovechando del sueño de Heinz y Reátegui, la mujer había conseguido escaparse rocambolescamente y refugiarse, primeramente en un pequeño caserío kukama, y luego en Iquitos, donde se había enterado de que estaba embarazada. Había decidido entonces volver a su comunidad y:

Cuando su hijo nació, tres meses después de llegar ella a su pueblo, cundió la noticia que ese niño de pelo rubio, de ojos marrones y piel clara era hijo de un puca bufeo, de un delfín colorado que se había acostado con ella haciéndose pasar por un hombre. Guardó el secreto durante cuatro años hasta esa mañana en que, llorando de dolor y furia, confesó que ese niño era hijo de Hans Heinz y clamó, por favor, que no lo mataran porque ese pequeño inocente no tenía la culpa de nada en el drama que a ella le había tocado vivir en Hamburgo. Cuando terminó de contar su historia las mujeres lloraban y los hombres tenían los puños cerrados. (Rumrrill, 2012, p. 141)

La sensación de vergüenza por el ultraje sufrido, guardada durante años bajo la protección de la realidad simbólica alternativa, podía entonces caer para revelar el cruel episodio de violencia.

Algo parecido acontece en Paiche, cuando Mañuca, la mujer de Sojo Arimuya, da a luz a un "niño de cara morateada, de descomunal cabeza cubierta de rubios cabellos, de ojos azules y redondos, 
de boca grande y caída como la de un anciano [...], brazos larguísimos, tan desproporcionados que le llegaban casi hasta los pies" (Calvo de Araújo, 2012 [1963], p. 70). El nacimiento del niño deforme desata los rumores entre los habitantes de la comunidad, que van suponiendo que el padre sea un brujo malo, el mismo diablo, o algún yacuruna, es decir "gente del agua". Sin embargo, hay quien dice: "Esa mufer ha bibido con gringo, a mí no me cofudean" (Calvo de Araújo, 2012 [1963], p. 70).

Efectivamente, la muchacha, antes de casarse con Sojo, había sido seducida y engañada por un alemán, un nazi alcohólico escapado de Europa y que se había refugiado en la selva. Sojo, para que las voces sobre la deformidad del niño no afecten la serenidad de su mujer y de toda la comunidad, revela de manera explícita lo que había pasado, explicando que no se trata de ningún hijo de bufeo, sino del hijo de un hombre "degenerado, perdido, borracho y, quién sabe qué otros vicios tendría" (Calvo de Araújo, 2012 [1963], p. 71).

Sojo confiesa la triste realidad y no culpa a su compañera, sino al revés, afirma que se trata de una víctima, que no tiene ninguna responsabilidad y que no tiene por qué sentir vergüenza. Además, con el paso del tiempo, el amor de la familia y los cuidados del abuelo, don Roca, permiten que el niño se mejore hasta perder su deformidad.

\section{Conclusiones}

Cabe preguntarse finalmente por qué los dos autores revelan de una forma tan clara lo que habitualmente los relatos sobre el bufeo colorado esconden. La caída del tabú, la explicación de la metáfora, aunque en principio parecería desmentir los relatos de la tradición oral, se revela una estrategia que permite un acercamiento a la selva y a la filosofía indígena decididamente más profundo que el que se ha presentado en los primeros ejemplos literarios citados.

Los relatos sobre el bufeo colorado han surgido principalmente a raíz de eventos traumáticos y violentos, y han brotado como creación simbólica que tiene finalidades concretas: darle sentido a esos mismos traumas, mitigar el dolor y - principalmenteenseñar y educar.

Volver a proponer el relato sin una contextualización adecuada lleva a la pérdida de estas funciones sociales y no permite una aproximación efectiva a la realidad de los habitantes de la selva y sus maneras de interpretar el mundo. $\mathrm{Al}$ contrario, al asumir un punto de vista externo y superficial, se encuentra una tendencia hacia el replanteamiento de estereotipos exotizantes en los que la selva es descrita como un espacio de vicio, pasiones incontrolables, peligros mortales y engaños: es decir el "infierno verde".

La revelación del símbolo, el descubrimiento de lo que la metáfora encubría por parte de Calvo de Araújo y Rumrrill, es decir, la explicación de forma directa y sin mediaciones de la existencia de un acto de violación detrás de las relaciones entre bufeos y mujeres, parece situarse en una posición contraria: la selva y los seres que en ella viven, sus elementos constituyentes, no son los elementos peligrosos: el peligro nace de la ambigüedad con la que se establecen las relaciones entre las personas con la llegada de sistemas de aprovechamiento y explotación de la selva misma y de sus habitantes. En tal sentido, la deconstrucción del mito, además de cumplir con las finalidades originarias, permite un cambio de perspectiva al abordar el discurso sobre la Amazonía: ya no un infierno, pero tampoco un paraíso.

Las dos novelas analizadas, lejos de proponer una visión paternalista o idealizada, presentan así una imagen más realista sobre la floresta y la manera de interpretar el mundo de sus habitantes: un ambiente sumamente frágil, duramente afectado y amenazado por la manera humana de actuar, por la introducción de sistemas de depredación de sus recursos y la consecuente destrucción de su inmensa biodiversidad, donde las relaciones sociales muchas veces se vuelven desequilibradas: un espacio en el que es posible una armonía solamente si esta se basa en el respeto entre los seres que la habitan. 


\section{Notas}

1 Agradezco a los dos revisores anónimos de la primera versión de este texto por sus comentarios e indicaciones.

2 Definición acuñada con la colección de relatos del brasileño Alberto Rangel de 1908, titulada precisamente Inferno Verde (Rueda, 2003, p. 38), y consagrada por una larga serie de obras literarias y cinematográficas a lo largo de todo el siglo XX.

3 Los temas planteados en los párrafos 2 y 3 del presente ensayo han sido previamente abordados, con diversas diferencias, en Pau (2019a), capítulo 3.1 y acápite 3.1.1.

4 Agradezco al equipo de Radio Ucamara de Nauta, en especial a Leonardo Tello, Marilez Tello y Rita Muñoz, por las informaciones citadas en este ensayo y recopiladas en varias conversaciones mantenidas a partir del año 2011.

5 Para citar algunas de las muchas referencias sobre este tema en Pantaleón...: "soldado que llega a la selva se vuelve un pinga loca" o "A mí me sucede siempre: llegar a la selva y empezar a respirar fuego, sentir que la sangre hierve" (Vargas Llosa, 1981 [1973], pp. 11-12).

6 Referencias a la pusanga se encuentran también en Rumrrill (2012, p. 57) y Calvo de Araújo (2012, pp. 202-203).

7 Como afirma Rumrrill en las dedicatorias de la novela "A César Calvo de Araújo, el legendario Pintor de la Selva. Cumpliendo una promesa que alguna vez le hice, el personaje de su novela Paiche, Sojo Arimuya, sigue viviendo en La Virgen del Samiria" (Rumrrill, 2012, p. 5).

8 El afán por una existencia en equilibrio con los seres humanos y la naturaleza fue una constante a lo largo de la vida del autor, quien "[d]espués de una carrera llena de reconocimiento internacional, se asienta en la Amazonía donde decide vivir aislado de la 'civilización', formando una comunidad de relaciones equitativas entre hombres y mujeres trabajadores que llevó el nombre de Shapshico, pero la utopía no duró mucho pues Calvo enfermó de gravedad y tuvo que ser trasladado a Lima, donde finalmente murió el 21 de octubre de 1970" (Bendayán, 2014, p. 270).

9 Regan (1983) inserta a los bufeos colorados en su sección sobre "yacurunas".

\section{Referencias bibliográficas}

Barletti, J. (2004). Sexualidad en la Amazonía: la construcción del imaginario social. En E. Elías Valdeavellano y E. Neira Riquelme (Comps.). Salud reproductiva en la Amazonía: perspectivas desde la cultura el género y la comunicación (pp. 99-115). Minga-Perú.

Baum, V. (1961). El bosque que llora. Círculo de lectores.

Belaunde, L. E. (2005). El recuerdo de Luna. Género, sangre y memoria entre los pueblos amazónicos. Fondo Editorial de la Facultad de Ciencias Sociales de la Universidad Nacional Mayor de San Marcos.

Belaunde, L. E. (2018). Sexualidades amazónicas. Género, deseos y alteridades. La Siniestra ensayos.

Bendayán, C. (2014). El arte de un pueblo sin tiempo. En VV. AA. Iquitos (268-275). Telefónica del Perú.

Calvo de Araújo, C. (2012 [1963]). Paiche. PetroPerú.

Calvo Soriano, C. (1981). Las tres mitades de Ino Moxo y otros brujos de la Amazonía. Proceso.

Câmara Cascudo, L. (1999). Dicionário do folclore brasileiro (10. a ed.). Ediouro Publicações.

Casu, M. (2015). Educazione indigena in Perù. II concetto di interculturalità e la sua applicazione dell'elaborazione del materiale didattico. (Tesis para optar al título de Doctora en Estudios filológicos y literarios). Università degli studi di Cagliari, Cagliari, Italia. 
Chirif, A. (2004). El imaginario sobre la mujer loretana. En E. Elías Valdeavellano y E. Neira Riquelme (Comps.). Salud reproductiva en la Amazonía: perspectivas desde la cultura el género y la comunicación (pp. 59-79). Minga-Perú.

Cure Valdivieso, S. (2005). "Cuidado te mochan la cabeza". Circulación y construcción de un rumor en la frontera amazónica de Colombia, Perú y Brasil. (Tesis para optar por el grado de Magíster en Estudios Amazónicos). Universidad Nacional de Colombia, Leticia, Colombia. https://repositorio.unal.edu.co/handle/unal/9605

Descola, P. (2002). Antropología de la naturaleza. Instituto Francés de Estudios Andinos, Lluvia Editores.

Descola, P. (2004). Las cosmologías indígenas de la Amazonía. En A. Surrallés y P. García Hierro (Eds.), Tierra Adentro. Territorio indígena y percepciones del entorno (2535). IWGIA. https://www.iwgia.org/images/publications/0331_tierra_adentro. pdf

Descola, P. (2012). Más allá de naturaleza y cultura. Amorrortu Editores.

Galli, E. (2012). Migrar transformándose. Género y experiencias oníricas entre los Runas de la Amazonía ecuatoriana. Abya-Yala.

Hill, J. (1988). Rethinking History and Myth. Indigenous South American perspectives on the Past. Urbana, Chicago: University of Illinois Press.

Lévi-Strauss, C. (1955). Tristes tropiques. Plon.

Lévi-Strauss, C. (1962). La penseé sauvage. Plon.

Lévi-Strauss, C. (1964). Mythologique I. Le cru et le cuit. Plon.

Lévi-Strauss, C. (1966). Mythologique II. Du miel aux cendres. Plon.

Lévi-Strauss, C. (1968). Mythologique III. L'origine des manières de table. Plon.

Lévi-Strauss, C. (1971). Mythologique IV. L'homme nu. Plon.

Magalhães Lima, D. de (2014). O Homem branco e o boto: o encontro colonial em narrativas de encantamento e transformação (Médio rio Solimões, Amazonas). Teoria e Sociedade. Número Especial: Antropologias e Arqueologias, 173-201. https:// www.mamiraua.org/ documentos/8e2315f5541366281c8757073a82de99.pdf.

Marcone, J. (1998). De retorno a lo natural: La serpiente de oro, la "novela de la selva" y la crítica ecológica. Hispania, 81 (2), 299-308. https://doi.org/10.2307/345018

Motta, A. (2011). La "charapa ardiente" y la hipersexualización de las mujeres amazónicas en el Perú: perspectivas de mujeres locales. Sexualidad, Salud y Sociedad. Revista Latinoamericana, 9, 29-60. https://doi.org/10.1590/S198464872011000400003

Omacha [Fundación]. (2004). Historias de bufeos. Bogotá: Ediciones Antropos.

Pau, S. (2017). Modelos para la superación de la crisis del sistema capitalista: Paiche y $E$ venne il sabato, novelas amazónicas. Revista de Crítica Literaria Latinoamericana, 43(86), 277-300.

Pau, S. (2019a). Más antes, así era. Literaturas del caucho en la Amazonía peruana. Pakarina ediciones.

Pau, S. (2019b). Más allá del "infierno verde" y del "paraíso perdido". Paisaje y perspectiva medioambiental en dos novelas amazónicas peruanas. En S. Regazzoni y F. Cecere (Eds.). América: el relato de un continente (pp. 107-122). Edizioni Ca' Foscari. https://doi.org/10.30687/978-88-6969-319-9/010.

Pau, S. (2020). El castellano amazónico en la novela Paiche. Análisis dialectológico. Lexis. Revista de Lingüística y Literatura, 43(1), 245-267. https://doi.org/10.18800/ lexis.202001.008

Pineda Camacho, R. (2010). Lévi-Strauss y la historicidad del mito. Maguaré. Homenaje a Claude Lévi-Strauss (Bogotá), 89-111.

Pratt, M. L. (2010). Ojos imperiales. Literatura de viajes y transculturación. Fondo de Cultura Económica.

Rama, Á. (2008). Transculturación narrativa en América Latina. Ediciones El Andariego.

Reeve, M. E. (1988). Cauchu Uras: Lowland Quichua Histories of the Amazon Rubber Boom. En J. Hill (Ed.), Rethinking History and Myth. Indigenous South American perspectives on the Past (18-34). University of Illinois Press. 
Regan, J. (1983). Hacia la tierra sin mal. Estudio sobre la religiosidad del pueblo en la Amazonía. Centro de Estudios Teológicos de la Amazonía.

Rivera Cusicanqui, S. (2010). Ch'ixinakax utxiwa. Una reflexión sobre prácticas y discursos descolonizadores. Tinta Limón Ediciones.

Rueda, M. H. (2003). La selva en las novelas de la selva. Revista de Crítica Literaria Latinoamericana, 29(57), 31-43. https://doi.org/10.2307/4531250.

Rumrrill, R. (2012). La Virgen del Samiria. Lima: Ediciones El Nocedal.

Slater, C. (1994). Dance of the Dolphin. Transformation and disenchantment in the Amazonian imagination. The University of Chicago Press.

Tello, L. (2014). Ser gente en la Amazonía, fronteras de lo humano: aportes del pueblo kukama. En R. Badini (Ed.), Amazzonia indigena e pratiche di autorappresentazione (39-48). Franco Angeli.

Turner, T. (1988). Commentary: Ethno-Ethnohistory: Myth and History in Native South American representations of contact with Western Society. En J. Hill (Ed.), Rethinking History and Myth. Indigenous South American perspectives on the Past (pp. 235-81). University of Illinois Press.

Urteaga Cabrera, L. (1995). El universo sagrado. Lima: Peisa.

Valenzuela, P., \& Valera, A. (2004). Koshi Shinanya Ainbo. El testimonio de una mujer shipiba. Fondo Editorial de la Universidad Nacional Mayor de San Marcos.

Varela Tafur, A. (2004). ¿Amazonas o mujeres de carne y hueso? O cómo fueron "vistas" las mujeres en la literatura de la Amazonía peruana. En E. Elías Valdeavellano y E. Neira Riquelme (Comps.), Salud reproductiva en la Amazonía: perspectivas desde la cultura el género y la comunicación (pp. 81-97). Minga-Perú.

Vargas Llosa, M. (1981 [1973]). Pantaleón y las visitadoras. Seix Barral.

Viveiros de Castro, E. (2004). Perspectivismo y multinaturismo en la América indígena. En A. Surrallés \& P. García Hierro (Eds.), Tierra Adentro. Territorio indígena y percepciones del entorno (37-80). IWGIA. https://www.iwgia.org/images/ publications/0331_tierra_adentro.pdf

Viveiros de Castro, E. (2010). Metafísicas caníbales. Líneas de antropología postestructural. Katz Editores. 